\title{
In situ behavioral plasticity as compensation for weather variability: implications for future climate change
}

\author{
Michael J. Noonan • Chris Newman . \\ Andrew Markham . Kirstin Bilham . \\ Christina D. Buesching - David W. \\ Macdonald
}

Received: date / Accepted: date

\begin{abstract}
While climatic effects on species biogeographic distributions are well documented, less mobile species must compensate for climate change in situ via behavioral plasticity. Despite this being a critical mechanism, behavioral plasticity is rarely modeled explicitly. Here we use novel accelerometer and active-RFID transponder technology to quantify weather-driven modification of activity, mechanical energy expenditure, and ranging behavior, using the European badger as a model species. We then examine how these behaviors could respond to future climate change. From multi-model inference, activity was promoted significantly by a quadratic relationship with temperature, but inhibited by a quadratic relationship with humidity, and the amount of solar radiation. Drier conditions also encouraged more movement. Modeled against IPCC SRES low and high emissions climate change scenarios, milder and drier conditions projected for the next century would likely produce a change to badgers' current phenology, with elevated levels of activity being maintained into the winter. This increased activity could necessitate up to a $15 \%$ increase in energy expenditure. Furthermore, conditions projected under the high emissions scenario may also lead to substantially increased movement, with implications for road traffic mortality rates. We contend that behavioral adaptation must be better incorporated into conservation strategies, versus the assumption of non-adaptive failure.
\end{abstract}

Michael J. Noonan

Smithsonian Conservation Biology Institute, National Zoological Park, 1500 Remount Rd., Front Royal, VA 22630, USA

Tel.: +1 540-635-0033

E-mail: NoonanM@si.edu

Michael J. Noonan · Chris Newman · Kirstin Bilham · Christina D. Buesching · David W. Macdonald

Wildlife Conservation Research Unit, Department of Zoology, University of Oxford, The Recanati-Kaplan Centre, Tubney House, Abingdon Road, Tubney, Abingdon, Oxfordshire, OX13 5QL

Andrew Markham

Department of Computer Science, University of Oxford, Wolfson Building, Parks Road, Oxfordshire, OX1 3QD. 
Keywords IPCC Scenarios - UKCP - Climate projection - Behavioral compensation · Energetics · Adaptation

\section{Introduction}

Rapid, anthropogenic climate change (IPCC, 2014) risks exposing species to evolutionarily novel situations (Diffenbaugh and Field, 2013), which can impair energetic balance (Chevin et al, 2010), and/or reduce fitness (Hellmann and PinedaKrch, 2007), compromising the species' realized niche (Quintero and Wiens, 2013). Many studies on climate change effects assume individuals will continue to perform the same routines, eat the same diet, and generally expend energy in the same way (e.g., Keith et al, 2008; Scheffers et al, 2016). Clearly, this is unrealistic (Smit et al, 2000). While more mobile species can shift their use of habitats to allow current behavioral regimes to continue to function (Walther et al, 2002; Barnosky and Kraatz, 2007), less mobile species, and/or those tied to specific habitats, must contend with changing conditions in situ (Campbell et al, 2012) through differential genetic trait selection (Visser, 2008), changes in population dynamics (Walther et al, 2002), or behavioral plasticity (Kearney et al, 2009; Beever et al, 2017).

Genotypic adaptation, via Darwinian selection, takes generations to occur (Barnosky and Kraatz, 2007), a factor that is particularly challenging for species with longer inter-generational times (Rosenheim and Tabashnik, 1991). Consequently, behavioral plasticity provides the most immediate tactical response to changing conditions (Bradshaw and Hardwick, 1989; Walther et al, 2002; Kearney et al, 2009; Sih et al, 2011). Behavioral responses are also less permanent than genetic selection, and thus better suited to temporary, or stochastic changes (Bradshaw and Hardwick, 1989; Chevin et al, 2010). Not all behaviors can be modified, however, particularly those tied tightly to ensuring reproduction/fitness (Visser, 2008), or dependent on inter-specific relationships (Cahill et al, 2012). In this respect, generalist species are more likely to respond through behavioral plasticity within their lifetimes, while rigid strategists are biased toward differential selection for phenotypes better fitting transformed conditions (Visser, 2008). Despite well documented coarse-scale adaptations to global climate change (Walther et al, 2002; Settele et al, 2014), a finer-scale mechanistic understanding of behavioral responses is lacking (Sih et al, 2011; Newman and Macdonald, 2015; Beever et al, 2017). This is problematic, as many conservation initiatives aimed at mitigating climate change impacts could benefit from considering species' capacities for behavioral plasticity (Beever et al, 2017).

Here, we address this research gap by identifying facets of animal behavior that exhibit plasticity in response to proximate weather conditions, and examine how these might respond to future climate change. We base our study on recent technological advances permitting the fine-scale measurement of location, and activity in free-ranging animals. Specifically, we employ tri-axial accelerometers, able to derive overall dynamic body acceleration (ODBA), an accurate measure of activity (Noonan et al, 2014; McClune et al, 2015), and a reliable proxy for energy expenditure (Wilson et al, 2006). We also use an animal-borne active-RFID tracking system, combined with a sensor network, to log the locations of tagged animals in near real-time (Noonan et al, 2015a). We pair these novel technologies with predictive models, based on the IPCCs climate change scenarios (Nakicenovic and 
Swart, 2000), that permit the simulation of weather conditions predicted under future climate change at fine temporal scales (Murphy et al, 2009; Sexton et al, 2016). Using these tools, we perform a series of empirically guided simulations aimed at identifying how behavior could be expected to respond to future climate change. Although these are inherently simplistic, given the potential for extreme weather events, limitations on accelerometer deployment duration and unforeseen behavioral accommodation or novel circumstances, we nevertheless illustrate how energy expenditure and behavior could respond to projected changes in weather conditions, and whether adaptations are likely to be sustainable.

\subsection{Model species: The European badger}

European badgers (Meles meles, henceforth 'badgers') have provided an informative model for studying responses to climate change (Macdonald and Newman, 2002; Macdonald et al, 2010; Nouvellet et al, 2013; Noonan et al, 2014; Newman et al, 2017). They are adaptable generalists, tied to communal burrows (termed 'setts') within forest and forest/agrarian habitats, and are generally not prone to extensive dispersal (Macdonald et al, 2015). To date, climate change has generally benefited population success (Macdonald and Newman, 2002; Newman and Macdonald, 2015), however there is currently no clear understanding of the behavioral mechanisms behind these benefits. Much of their climatic sensitivity results from feeding principally on earthworms (Lumbricus spp.). Earthworms are sensitive to micro-climatic conditions (Curry, 2004), and their distribution and availability to consumers depend heavily on weather conditions (Kowalczyk et al, 2003). Furthermore, if poor weather and low food availability persist, badgers can mitigate the costs of poor foraging returns by remaining underground in their thermally-stable setts (Tsunoda et al, 2018) and entering torpor (Noonan et al, 2014). In addition to foraging however, territorial, social, and mating interactions motivate individualspecific activity (Annavi et al, 2014; Tinnesand et al, 2015), and individuals must trade these off against net losses to body-condition resulting from prolonged activity, particularly on energetically costly nights (Noonan et al, 2014). Consequently, we focus on the critical pre-torpor autumn season, when body-fat is accumulated. Because badgers cannot survive within their setts indefinitely without leaving to forage, we anticipate that to maintain energetic equilibrium in response to prevailing conditions, individuals will attempt to balance their above-ground activity versus remaining within the thermal refuge of their setts (Noonan et al, 2014).

\section{Methods}

This study was conducted in Wytham Woods, Oxfordshire (GPS reference: $51^{\circ} 46^{\prime} 26^{\prime \prime} \mathrm{N}$; $1^{\circ} 19^{\prime} 19^{\prime \prime}$ W); a 424-ha mixed semi-natural woodland designated as a Site of Special Scientific Interest (SSSI), and managed by the University of Oxford. The resident, high-density badger population was comprised of 23 social groups with ca. 145 adults and 52 cubs in 2014 (Noonan et al, 2015b).

As part of a long-term research program (Macdonald et al, 2015), in August, 2014, 10 badgers ( 5 males and 5 females; Online Resource 1), resident at three 
adjacent social groups, were caught, sedated and measured. Body-Condition Indices (BCI; a measure of stored body-fat; Noonan et al, 2014) were calculated as the ratio between $\log$ (mass) and $\log$ (body-length). Following Woodroffe and Macdonald (1995), female reproductive status was inferred from vulva condition; classified as oestrus (vulva swollen and moist), or non-oestrus (vulva flat and dry). All males had scrotal testes when collared in August and inferred to be in breeding condition (Buesching et al, 2009). In autumn, however, both sexes enter a period of reproductive quiescence, thus reproductive motivation likely changed over the study period. Nevertheless, there are distinct physiological costs associated with maintaining reproductive condition (Woodroffe and Macdonald, 1995; Buesching et al, 2009) that persist after the mating season itself, incurring ongoing costs throughout this study.

All captured badgers were fitted with custom-built tracking tags, including triaxial accelerometers and active radio-frequency identification (aRFID tags; Noonan et al, 2015a; Ellwood et al, 2017). Tags were mounted onto commercially available padded leather dog collars, with a complete assembly weight of $95 \mathrm{~g}$. Badgers were released at their place of capture after a $3 \mathrm{~h}$ recovery period. All procedures undertaken for this study were authorized by both Natural England (2014-5710-SCI-SCI), and Home Office licenses (PPL 30/2385), and approved by the University of Oxford's Animal Welfare and Ethical Review Board, and all personnel handling animals were qualified Personal Individual License (PIL) holders.

\subsection{Quantifying variation in activity}

Accelerometers sampled relative acceleration, at a frequency of $8 \mathrm{~Hz}$, across three axes (heave, surge, and sway). Data were compressed and stored onboard collars, and communicated wirelessly to base-stations (see below). Behavior was quantified via accelerometer readings in two ways: i) Overall Dynamic Body Acceleration (ODBA; in $g$ ), provided a proxy for energy expenditure (Wilson et al, 2006). ODBA values have been established to correlate with an individual's $\mathrm{O}_{2}$ consumption and $\mathrm{CO}_{2}$ production, related to metabolic rate (Wilson et al, 2006); and ii) 'activity', as a binary measure of above-ground activity versus inactivity underground, based on an ODBA threshold value of 0.313g (Noonan et al, 2014, see also Online Resource 2). Data were collected from August 16, 2014, until Nov 7, 2014. Across all 10 animals, over $3.5 \times 10^{8}$ accelerometer data points were generated over 522 'badger days'.

\subsection{Quantifying movement patterns}

The three focal social groups occupied nine setts (three main, and six outlying; Fig. 1) across ca. 49 ha. We installed $2.4 \mathrm{GHz} 802.15 .14$ (Zigbee) base-station receivers at each sett (Noonan et al, 2015a). Base-stations received aRFID tag signals, broadcast every $3 \mathrm{~s}$, whenever an animal was within a $20-25 \mathrm{~m}$ radius detection range. When a collar was detected, an entry was generated, consisting of collar ID, time-stamp, and received signal strength. Buffered data were transferred from collars to base-stations and saved for later retrieval. Due to the way setts were distributed within the study area, it was possible for an individual to be within 
the detection range of multiple base-stations simultaneously. In these instances, a badger was recorded at the location where it registered the strongest signal. In total, 103,797 (re-)visits to setts were recorded over 552 'badger days'.

There was substantial variation in the number of setts individuals visited each night, and their frequency of (re-)visits. We used sett proximity data to calculate nightly occurrence distributions (i.e., the area an animal occurred during the sampling period; Fleming et al, 2016, hereafter 'inter-sett visits'), using the Brownian bridge kernel density estimation method in the $\mathrm{R}$ package AdehabitatHR (Calenge, 2006). This method uses a conditional random walk between successive pairs of locations, based on Brownian motion, to provide an estimate of where the animal was likely to have occurred during the time of observation (Horne et al, 2007). For each badger, the Brownian motion variance parameter $\sigma^{1}$ was calculated using the maximum likelihood approach developed by Horne et al. (2007), while $\sigma^{2}$, a measure of the distribution of location errors, was set to $50 \mathrm{~m}$ (i.e., the maximum aRFID detection diameter). It should be noted that these estimates are limited by the sub-sampling inherent in this tracking approach (i.e., badgers could not have been recorded unless in the detection array), and do not represent their full home range (sensu Burt, 1943). Nonetheless, these occurrence distributions provide a robust estimate of variation in the nightly propensity towards extra-group visits.

\subsection{Weather conditions}

Meteorological records were obtained from the UK Environmental Change Network (ECN) weather station in Wytham Woods (terrestrial site T08). To quantify the effects of contemporaneous weather on badger activity, we used weather variables known to influence badger behavior (Johnson et al, 2002; Macdonald et al, 2010; Noonan et al, 2014, 2015b), recorded at hourly intervals: (1) mean solar radiation, providing a measure of photoperiod (solar; in $\mathrm{W} / \mathrm{m}^{2}$ ), with the additional benefit of including cloud cover influences on dusk emergence; (2) mean relative humidity $\left(\mathrm{RH}\right.$; in percent); (3) mean air temperature (temp; in ${ }^{\circ} \mathrm{C}$ ); and (4) rainfall (rain; in $\mathrm{mm}$ ).

In addition, in Online Resource 3 we present analyses of trends in historic weather data from 1853 to 2015, providing the range of conditions the ancestors of this population were exposed to, shaping their selection. In Online Resource 4, we present analyses of the sett micro-climate over the course of the study period.

\subsection{Statistical analyses}

All statistical analyses were conducted in the $\mathrm{R}$ environment (version 3.3.2; $\mathrm{R}$ Core Team, 2016). Initial descriptive analyses included analyses of variance (ANOVA) and covariance (ANCOVA), as well as Pearson's correlations. To summarize the variance in these data, we ran a Principal Component Analysis (PCA), performed over mean daily data. Here, sex was included as a supplementary qualitative factor, without rotation, and instances with missing values were excluded $(n=482)$.

To investigate the relationship between ODBA and movement response variables and weather, we fit linear models using a generalized least squares approach, via the R package nlme (v 3.1-131; Pinheiro et al, 2013). For the binomial activity 
data, models were fit using generalized estimation equations via the $\mathrm{R}$ package geepack ( $\mathrm{v}$ 1.2-1; Halekoh et al, 2006). To test whether activity and ODBA responded to variation in weather or biological variables, models were fitted across mean hourly data $(n=12,546)$. To examine variation in movement patterns, models were fitted to data at the daily scale $(n=482)$. All variables were mean centered prior to analyses. To correct for a positive skew, inter-sett visit data were log-transformed. To account for the temporal autocorrelation introduced by the serial nature of these data, models predicting activity and ODBA included a first order autoregressive process for the residuals, and models predicting inter-sett visits included a first order autoregressive process and a first order moving average. The autoregressive terms $(\phi)$ specify that the response variable depends linearly on previous values, with the order identifying the number of lags that should be considered, and the moving average term $(\theta)$ that the variable depends on both current and past values (Hamilton, 1994). The most appropriate error term for each model was identified by model selection techniques, with independent errors as the null model. We included the random effect of individual in all of our models, and examined a consistent set of linear and quadratic effects across all response variables:

$y=f\left(\right.$ solar + temp + temp $^{2}+\mathrm{RH}+\mathrm{RH}^{2}+$ rain + rain $^{2}+$ sex + reproductive status + BCI + Group)

From these global models, we specified subsets of candidate models comprised of all possible combinations of fixed effects, both with and without two-way interaction terms. We then calculated the likelihood of each model, and used the small sample size corrected Akaike's Information Criterion (AICc), to rank candidate models according to their statistical support (Burnham et al, 2011), using the $\mathrm{R}$ package MuMIn (v. 1.15.6; Barton, 2016). The model with the lowest AICc value was selected as the most supported. Note, the activity models were fit using quasi-likelihood (Halekoh et al, 2006), and so model selection was based on quasi-information criterion (QIC). Model selection tables are presented in Online Resource 5.

\subsection{Climate change projections}

We used these empirically derived models to inform simulations of how future climate change could affect badger behavior. We acknowledge the limited range of energetic data supporting these simulations relative to the full potential variability of future weather and reiterate our premise that the ultimate range of adaptive responses an animal might make is an unknown; nevertheless energetic models are relevant in principle and warrant development as a tool for assessing species' vulnerabilities to climate change. With this in mind, we kept our metrics of badger responses deliberately coarse, pertaining only to ODBA, Activity and Movement, because badgers can reliably be anticipated to continue to seek to optimize energy budgets (foraging vs expenditure). Using the UK Climate Projections 2009 (Murphy et al, 2009) web interface, we simulated weather data for the $25 \mathrm{~km}^{2}$ area around the study site. Weather was projected based on the IPCC's SRES low 


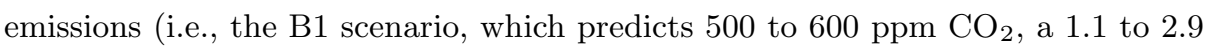
${ }^{\circ} \mathrm{C}$ rise in mean temperature, and no significant trends in precipitation), and high emissions scenarios (i.e., the A1F1 scenario, which predicts 550 to $750 \mathrm{ppm} \mathrm{CO}_{2}$, a 2.4 to $6.4{ }^{\circ} \mathrm{C}$ rise in mean temperature, a 0 to $5 \%$ decrease in relative humidity, and no significant trends in precipitation; Nakicenovic and Swart, 2000). Although more recent Representative Concentration Pathway (RCP) models have since replaced the SRES emissions scenarios (Moss et al, 2010), we chose to simulate from SRES based models due to the availability of open source tools for working with these models (Murphy et al, 2009), whereas these tools are not currently available for RCP models. Notably, recent analyses have demonstrated how the UKCP09 SRES based projections still provide reliable weather projections when compared to RCP projections, particularly with respect to temperature and precipitation (Sexton et al, 2016). For each scenario, we simulated mean hourly values for seven overlapping, 2-decade time-periods (from 2010 to 2099), with 100 replicates for each time-period (i.e., 700 replicates per scenario, each with $n=1,638$ hours of simulated weather data).

We then applied the R environment's predict () function to the most supported model for each behavioral response variable, to illustrate how these three behaviors could respond to projected weather conditions. We note, that although response trends can be considered as robust, both our parameter estimates and climate predictions are subject to modeling error, and exact values should be treated with caution.

\section{Results}

\subsection{Summary of activity and movement data}

Badgers were active for a median 7.6 hours per night (range: $0.0-11.2$ ), and, superficially (but see below), there was no evidence of a linear trend in activity over the study period ( $r<0.01, n=552, P=0.58)$. There were significant differences in duration of nightly activity between individuals $\left(F_{[9,542]}=5.54, P<0.001\right)$, but no difference between sexes $\left(F_{[1,550]}=0.09, P=0.77\right)$. Individuals also exhibited significant differences in nightly ODBA expenditure $\left(F_{[9,542]}=50.26, P<0.001\right)$, with a significant sex effect $\left(F_{[1,550]}=5.65, P=0.02\right)$, where males tended to have a lower ODBA than females. The rates at which individuals visited setts also differed significantly between individuals $\left(F_{[9,707]}=14.09, P<0.001\right)$, with males visiting significantly more setts than did females $\left(F_{[1,715]}=23.03, P<0.005\right)$.

Only the first four components in a PCA across mean daily data warranted retention. These explained a cumulative $69.8 \%$ of the variance in these data (Table 1). From factor loadings, reproductive status, activity/ODBA budgets, and weather variables were the most influential parameters. Projecting these data into the reduced dimension space defined by PC 1, which was defined primarily by energy budget variables, and PC 2, which was dominated by weather variables, revealed minimal overlap between sexes, within which individuals in different reproductive condition grouped into relatively distinct clusters (Fig. 2). 


\subsection{Modeling variation in activity}

From our modeling framework, we found that weather conditions were crucial for predicting the amount of time spent active, versus inactive underground, how much energy individuals expended on a night to night basis, and how many visits were made to neighboring groups (Table 2). Indeed, all the selected behavioral models included weather effects.

Model selection revealed that sex, reproductive status, the amount of solar radiation, quadratic terms for temperature and humidity and the interactions between solar radiation and sex, and quadratic temperature and sex were the most influential predictors of the duration of nightly activity. From parameter estimates, warmer, less humid conditions tended to result in badgers spending more hours active each night. In contrast, when modeling ODBA, while solar radiation, temperature, and humidity were still included in the most supported model, here rainfall, and all of the biological parameters, as well as interactions between these, also proved influential. From parameter estimates, humidity and temperature correlated negatively with ODBA, whereas rainfall had a positive effect. Interestingly, BCI also had a negative on ODBA such that animals in better condition tended to spend less energy per night. When modeling variation in nightly inter-sett visits, rainfall, and humidity (both linear and quadratic), as well as the interactions between these, were the only weather parameters that were selected. Of the biological parameters, only BCI and sex warranted retention. From parameter estimates, drier nights tended to result in more inter-sett visits, where individuals with higher BCI tended to visit more setts. In addition, males tended to move between setts more often than females.

\subsection{Climate change projections}

Predicted climate change through the 21st Century appears likely to drive adaptive changes in coarse metrics of badger autumnal phenology. Modestly warmer conditions under the the low emissions scenario could cause a net increase in the duration of nightly activity (median $=21.6 \%$ increase, 95\% CIs $21.5-22.0$ ), with activity being maintained into the winter months (Fig. 3a). Although the net amount of energy expended while active would be only marginally greater than current levels (median $=0.46 \%$ increase, 95\% CIs $0.43-0.49$; Fig. 3b), models project that ODBA through November could be $15.6 \%$ greater (95\% CIs 15.5 15.7). Under this scenario, activity and ODBA adjustments would be accompanied by only a small increase (median $=1.29 \%$; 95\% CIs $1.22-1.37$ ) increase in inter-sett visits (Fig. 3c). In contrast, under a high emissions scenario, warmer and less humid conditions might bring about a far greater (median $=98.9 \%$; 95\% CIs 98.6 - 99.2) increase in nightly activity duration (Fig. 3d), but with negligible net changes in the amount of energy spent while active (median $=-0.16 \%$ increase, 95\% CIs -0.19 - -0.13; Fig. 3e), however, again, late autumn/winter ODBA was projected to be $15.0 \%$ (95\% CIs $14.88-15.14$ ) greater by November. Interestingly, this scenario predicted a median 3.30\% (95\% CIs 3.21 - 3.41) increase in inter-sett visits (Fig. 3f), with the potential for substantially more movement anticipated in early autumn. 


\section{Discussion}

Schloss et al. (2012) predict that, for the western hemisphere, an average of $9.2 \%$ of mammals at any given location will be unable to respond to climate change adequately - in some regions up to $39 \%$ may be unable to keep pace. Our study demonstrates, however, that when making predictions about future populations, it is not appropriate to assume changes from current normative conditions will exceed the adaptability of the species. Furthermore, we illustrate that the consequences of behavioral plasticity for energy expenditure will likely follow non-linear trajectories with warming trends. It is thus crucial to better understand how species may respond to the cascade of stressors resulting from climate change via innate behavioral plasticity (Bradshaw and Hardwick, 1989; Chevin et al, 2010; Noonan et al, 2014).

From our ODBA and tracking data, we found that badgers exhibited unified responses to the main weather types: i) when conditions were warm and dry individuals were active for longer - these conditions are less conducive to earthworm emergence (Curry, 2004), and result in reduced foraging returns (Kowalczyk et al, $2003)$; ii) when it was mild and dry, individuals also tended to move over larger areas - likely because more foraging effort was required when earthworms were less abundant; and iii) under cool, dry conditions, badgers were significantly less active - extended periods of activity would risk net-negative energetic returns during conditions of low(er) earthworms availability, with respect to thermoregulatory costs (Noonan et al, 2014). These tactical responses suggest badgers adapt their activity in relation to optimize food intake and minimize wasteful energy expenditure.

This tactical reliance on innate behavioral plasticity evidenced in this study reveals, mechanistically, that badger responses to prevailing weather have, thus far, been sufficient to ensure the perpetuation of this population (see also Macdonald et al, 2010; Nouvellet et al, 2013). Badgers have a recorded history of occupying this study-site for centuries (Macdonald et al, 2015), likely since the Holocene interglacial began (Sommer and Benecke, 2004). In terms of trends, meteorological records for this site commencing in 1853 reveal that the study area has undergone an incremental, $1.7^{\circ} \mathrm{C}$ increase in temperature (consistent with global trends; IPCC 2014); which, to date, has generally benefited population success (Macdonald and Newman, 2002; Newman and Macdonald, 2015). Although our current study took place in a comparatively low weather-stress year, historic records include a number of extreme weather event years (Online Resource 2). These harsh years likely impacted the population severely (see Nouvellet et al, 2013), but evidently the population remained viable, illustrating the intrinsic resilience this species can exhibit, allowing populations to survive even severe weather stress.

In terms of what this may mean for future responses to changing climate, firstly we emphasize that essentially we project a histriology here; if the weather became such, badgers might plausibly respond thus. Predictors and responses here are both complex and crucially, all of our models included non-linear relationships with weather parameters, exemplifying why simple linear responses to climate change should not be assumed (Doak and Morris, 2010; Oliver and Morecroft, 2014). Nevertheless, we present these energetic response models as illustrative and usefully indicative, warranting further development. Our projections indicated that both the low, and high emissions scenarios would likely to result in increased badger 
activity, and inter-sett visits. The associated increase in energy expenditure required to achieve this, particular in late autumn/early winter, is not insubstantial. Furthermore, changes in phenology could cause specific caloric requirements to be out of synchrony with seasonal food availability (Walther et al, 2002; Settele et al, 2014). Not least because badgers currently rely on periods of torpor to cope with weather/food stress. As reported for dormice (Muscardinus avellanarius; Pretzlaff and Dausmann, 2012) and microchiropterid bats (Foley et al, 2011), however, this strategy can become compromised if winters become too warm for metabolic rates to remain sufficiently suppressed (Newman and Macdonald, 2015). We acknowledge, however, that there are other complicating factors that are not captured in these models; hibernation/torpor are not only a response to weather conditions. These processes are also under endocrinological control via day-length, operating through the pineal hormone melatonin (Bechtold et al, 2012). Ability to respond to changing autumnal weather would thus have an interactive hormonal component, where day-length variation stays fixed with latitude. Despite these limitations, we advocate the refinement of energetic approaches to explore how adaptable species' bioclimatic niches may be in light of climate change, as a conservation tool.

There are also confounding issues arising from greater winter activity and increased movement. Macdonald et al (2010) describe how milder winter temperatures are linked to higher rates of badger road traffic accidents (RTAs), which are the primary cause of adult mortality in the urban UK. Our findings of modified activity patterns and ranging behavior provide a mechanistic understanding of this relationship. Consequently, although the weather conditions projected under future climate change might result in improved foraging conditions, and so greater activity (see also Noonan et al, 2014), the associated change in behavior may result in a net negative impact on the population due to increased rates of RTAs. This suggests that the rate of RTAs may become a conservation priority for this species if warming trends continue (see also Macdonald et al, 2010). Similarly, an analysis by Glista et al. (2008) of more than 60 vertebrate species revealed that temperature was the primary predictor of RTA mortality. Conversely, Rolandsen et al. (2011) found that for moose (Alces alces) populations, warmer winters result in fewer RTAs. They speculated that moose are cold-adapted, and thus maintain higher levels of activity at lower temperatures, demonstrating the importance of accounting for species- and situation-specific behavioral plasticity, precluding a 'one size fits all' approach.

Our findings, based on novel methods for quantifying activity, energy expenditure, and ranging behavior support a meta-analysis by Hendry et al. (2008) who concluded that, from over 3000 instances of phenotypic change rates, behavioral plasticity proved the most important response to climate change. Integrating the role of in situ compensation of climate change through plasticity in behavioral tactics must therefore become a climate-ecology and conservation priority (Bradshaw and Hardwick, 1989; Newman and Macdonald, 2015; Blumstein and Berger-Tal, 2015; Beever et al, 2017). As we have shown, this is especially important in regions where proximate weather conditions are highly variable, such as the UK, where the flexibility afforded by behavioral plasticity are most effective. 


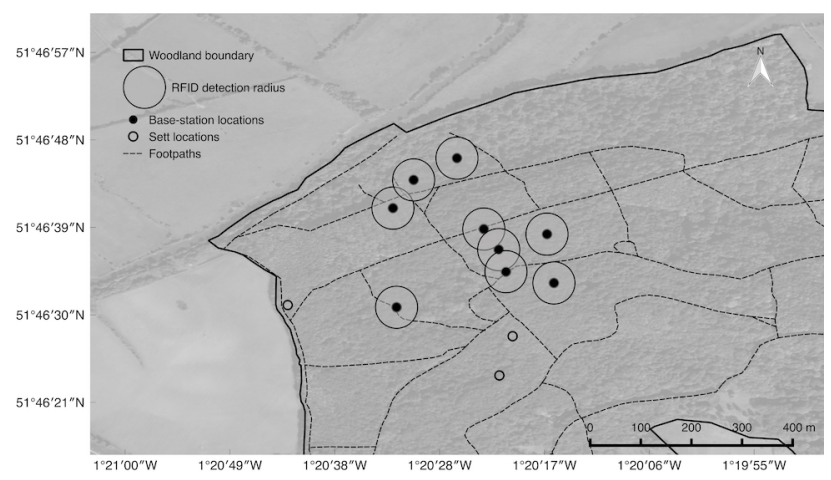

Fig. 1 Map of the study area within Wytham Woods, UK (GPS reference: 5146'26"N; $\left.1^{\circ} 19^{\prime} 19^{\prime \prime} \mathrm{W}\right)$, depicting the locations of aRFID base-stations at monitored sett sites, as well as unmonitored, nearby sett sites.

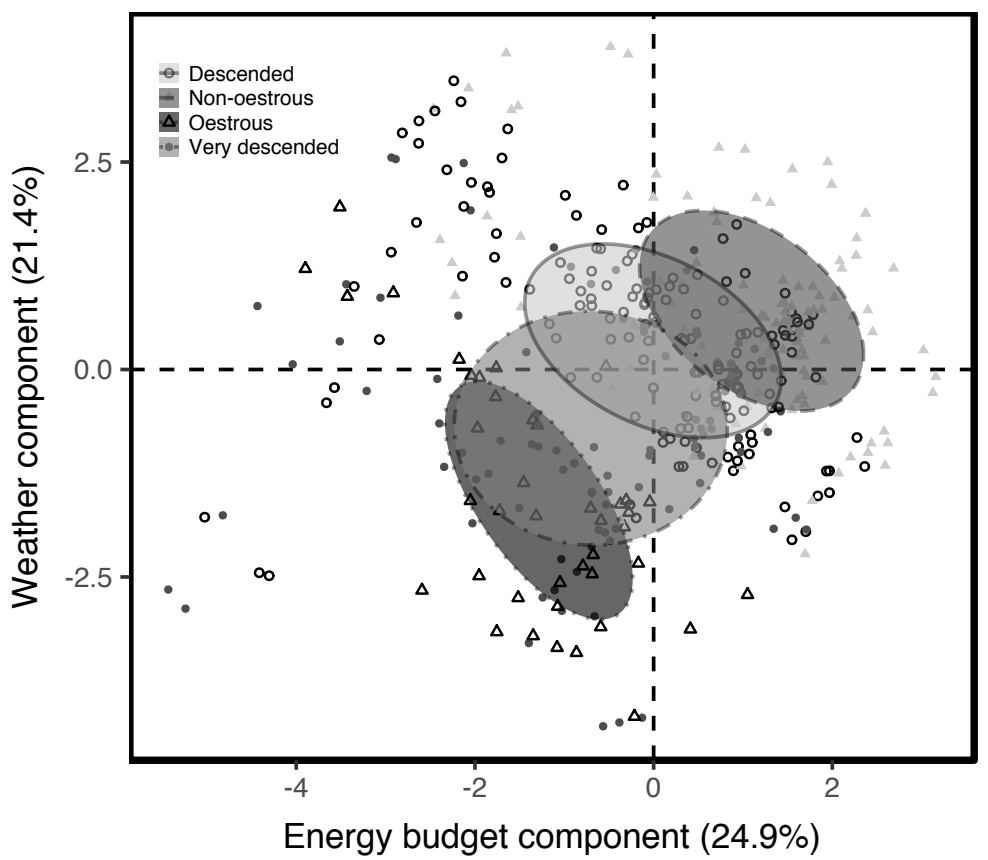

Fig. 2 Factor map of daily data projected in the reduced dimension space defined by the energy budget dominant PC 1 (x-axis) and the weather dominant PC 2 (y-axis) of a principal component analysis. Ellipsoids depict the variance for each reproductive status, centered on respective means. Percentages represent the amount of variation in these data that were accounted for by the respective components (detailed in Table 1). 

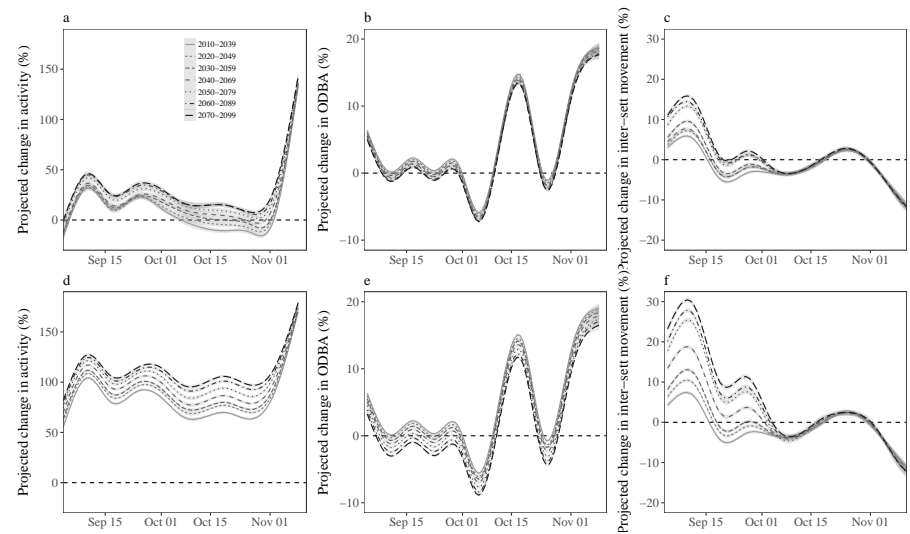

Fig. 3 The projected percent change in daily activity (Hrs); ODBA (g); and inter-sett movements (ha) under future climate projections over seven over-lapping time periods, in relation to present day trends. Panels a - c depict projected change in behavior under a low emissions scenario (IPCC SRES B1); $\mathrm{d}$ - $\mathrm{f}$ depict the projected change behavior under a high emissions scenario (IPCC SRES A1F1). Projections were based on the selected model for each response variable (see table 2 ). The vertical line at $y=0$ represents no change from the empirical data. Trend lines depict Loess smoothed regressions, and shaded areas represent the standard error of the curve fits. The trends in projected responses were generally consistent between scenarios, but the magnitudes of the changes were greater under the high emissions scenario.

Table 1 Summary of the first four components of a principal component analysis performed over mean daily data, with sex included as a supplementary qualitative factor. ODBA represents accelerometer derived overall dynamic body acceleration $(g)$, as a proxy for energy expenditure; and BCI the ratio of log scaled body weight to length.

\begin{tabular}{lrrrr}
\hline & PC 1 & PC 2 & PC 3 & PC 4 \\
\hline Eigenvalue & 2.49 & 2.14 & 1.44 & 0.91 \\
\% of variance explained & 24.94 & 21.42 & 14.42 & 9.07 \\
Cumulative \% of variance explained & 24.46 & 45.36 & 60.78 & 69.84 \\
& & & & \\
Factor loadings & & & & \\
Individual & -0.17 & -0.25 & -0.17 & 0.77 \\
BCI & 0.05 & $<0.01$ & 0.65 & -0.07 \\
Reproductive status & -0.34 & -0.31 & 0.20 & 0.20 \\
Hours active & 0.29 & 0.46 & $<0.01$ & 0.41 \\
ODBA & 0.41 & 0.48 & 0.02 & 0.11 \\
Temperature & 0.35 & -0.20 & 0.15 & 0.37 \\
Relative humidity & -0.43 & 0.33 & 0.06 & $<0.01$ \\
Rainfall & -0.36 & 0.35 & 0.02 & 0.06 \\
Solar radiation & 0.39 & -0.36 & -0.07 & -0.18 \\
Inter-sett visits & 0.02 & -0.02 & 0.69 & 0.09 \\
\hline
\end{tabular}




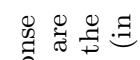

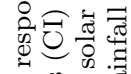

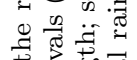

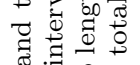

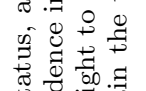

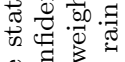

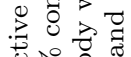

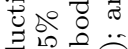

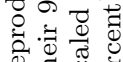

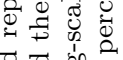

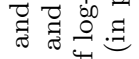

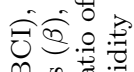

舟

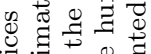

政它

范势

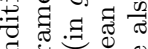

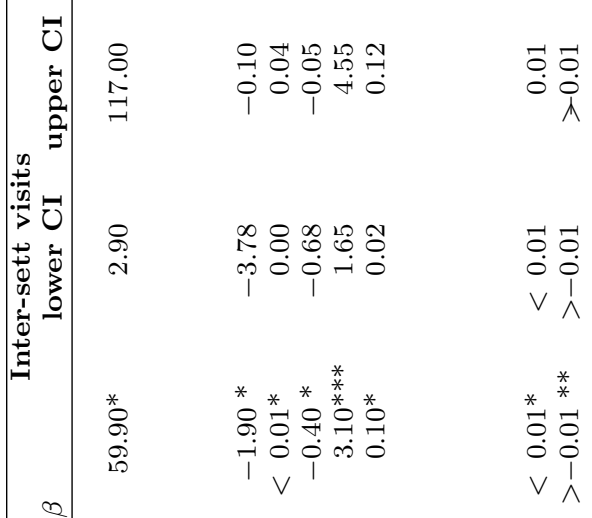

己

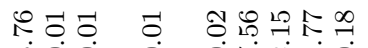

$\begin{array}{rlll}1 & 1 & 1 & 1 \\ 0 & 0 & 0 & 0\end{array}$

$\begin{array}{ccc}0 & \\ 0 & 5 \\ 0 & 0 & 1 \\ 0 & 1\end{array}$

कि

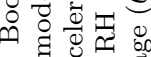

话芯芯范

is.

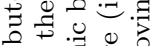

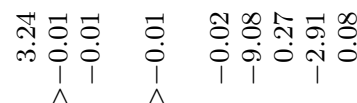

苗

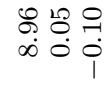

2

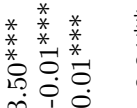

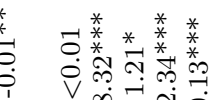

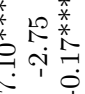

$\overrightarrow{\tilde{\sigma}}$

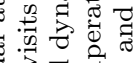

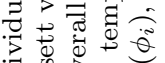

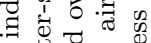

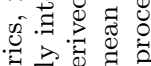

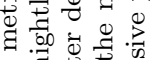

苛 :

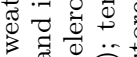

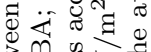

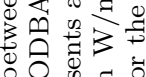

a:

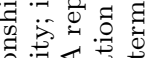

诺语

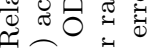

ง के

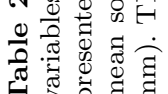

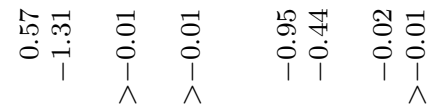

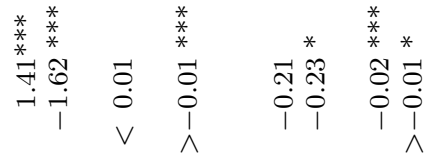

$\infty$

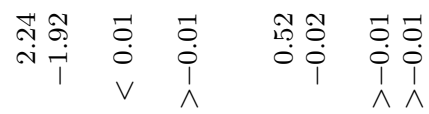

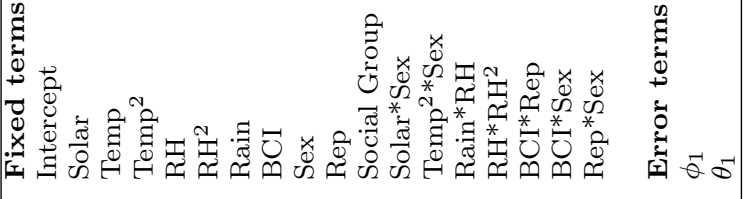


Acknowledgements We would like to thank The Peoples Trust for Endangered Species for supporting this core study, and Biotrack Ltd. for their expertise in manufacturing and assembling our custom tracking collars. MJN was supported by the Rhodes Trust and a Natural Sciences and Engineering Research Council of Canada postgraduate scholarship, and AM was supported by an Engineering and Physical Sciences Research Council grant: UndertrackerEP/I026959/1. The authors thank the Climatic Change editors and reviewers for suggestions that helped improved this manuscript.

\section{References}

Annavi G, Newman C, Dugdale HL, Buesching CD, Sin YW, Burke T, Macdonald DW (2014) Neighbouring-group composition and within-group relatedness drive extra-group paternity rate in the European badger ( Meles meles). Journal of Evolutionary Biology 27(10):2191-2203

Barnosky AD, Kraatz BP (2007) The Role of Climatic Change in the Evolution of Mammals. BioScience 57(6):523-532

Bartoń K (2016) MuMIn: Multi-Model Inference. R package version 1.15.6. https://CRAN.R-project.org/package=MuMIn

Bechtold DA, Sidibe A, Saer BRC, Li J, Hand LE, Ivanova EA, Darras VM, Dam J, Jockers R, Luckman SM, Loudon ASI (2012) A Role for the Melatonin-Related Receptor GPR50 in Leptin Signaling, Adaptive Thermogenesis, and Torpor. Current Biology 22(1):70-77

Beever EA, Hall LE, Varner J, Loosen AE, Dunham JB, Gahl MK, Smith FA, Lawler JJ (2017) Behavioral flexibility as a mechanism for coping with climate change. Frontiers in Ecology and the Environment 15(6):299-308

Blumstein DT, Berger-Tal O (2015) Understanding sensory mechanisms to develop effective conservation and management tools. Current Opinion in Behavioral Sciences 6:13-18

Bradshaw AD, Hardwick K (1989) Evolution and stress-genotypic and phenotypic components. Biological Journal of the Linnean Society 37(1-2):137-155

Buesching CD, Heistermann M, Macdonald DW (2009) Seasonal and interindividual variation in testosterone levels in badgers Meles meles: evidence for the existence of two endocrinological phenotypes. Journal of Comparative Physiology A 195(9):865-871

Burnham KP, Anderson DR, Huyvaert KP (2011) AIC model selection and multimodel inference in behavioral ecology: some background, observations, and comparisons. Behavioral Ecology and Sociobiology 65(1):23-35

Burt WH (1943) Territoriality and Home Range Concepts as Applied to Mammals. Journal of Mammalogy 24(3):346-352

Cahill AE, Aiello-Lammens ME, Fisher-Reid MC, Hua X, Karanewsky CJ, Yeong Ryu H, Sbeglia GC, Spagnolo F, Waldron JB, Warsi O, Wiens JJ (2012) How does climate change cause extinction? Proceedings of the Royal Society B: Biological Sciences 280(1750):20121890-20121890

Calenge C (2006) The package "adehabitat" for the R software: A tool for the analysis of space and habitat use by animals. Ecological Modelling 197(3-4):516519

Campbell RD, Nouvellet P, Newman C, Macdonald DW, Rosell F (2012) The influence of mean climate trends and climate variance on beaver survival and recruitment dynamics. Global change biology 18(9):2730-2742 
Chevin LM, Lande R, Mace GM (2010) Adaptation, Plasticity, and Extinction in a Changing Environment: Towards a Predictive Theory. PLoS Biology 8(4):e1000357

Curry JP (2004) Factors Affecting the Abundance of Earthworms in Soils. In: Edwards CA (ed) Earthworm Ecology, Boca Raton, pp 91-113

Diffenbaugh NS, Field CB (2013) Changes in ecologically critical terrestrial climate conditions. Science 341(6145):486-492

Doak DF, Morris WF (2010) Demographic compensation and tipping points in climate-induced range shifts. Nature 467(7318):959-962

Ellwood SA, Newman C, Montgomery RA, Nicosia V, Buesching CD, Markham A, Mascolo C, Trigoni N, Pásztor B, Dyo V, Latora V, Baker SE, Macdonald DW (2017) An active-radio-frequency-identification system capable of identifying co-locations and social-structure: Validation with a wild free-ranging animal. Methods in Ecology and Evolution 8(12):1822-1831

Fleming CH, Fagan WF, Mueller T, Olson KA, Leimgruber P, Calabrese JM (2016) Estimating where and how animals travel: an optimal framework for path reconstruction from autocorrelated tracking data. Ecology 97(3):576-582

Foley J, Clifford D, Castle K, Cryan P, Ostfeld RS (2011) Investigating and Managing the Rapid Emergence of White-Nose Syndrome, a Novel, Fatal, Infectious Disease of Hibernating Bats. Conservation Biology 25(2):223-231

Glista DJ, DeVault TL, DeWoody JA (2008) Vertebrate road mortality predominantly impacts amphibians. Herpetological Conservation and Biology 3(1):77-87

Halekoh U, Højsgaard S, Yan J (2006) The R package geepack for generalized estimating equations. Journal of Statistical Software 15(2):1-11

Hamilton JD (1994) Time series analysis, vol 2. Princeton University Press, Princeton

Hellmann JJ, Pineda-Krch M (2007) Constraints and reinforcement on adaptation under climate change: Selection of genetically correlated traits. Biological Conservation 137(4):599-609

Hendry AP, Farrugia TJ, Kinnison MT (2008) Human influences on rates of phenotypic change in wild animal populations. Molecular ecology 17(1):20-29

Horne JS, Garton EO, Krone SM, Lewis JS (2007) Analyzing animal movements using Brownian bridges. Ecology 88(9):2354-2363

IPCC (2014) IPCC Fifth Assessment Synthesis Report - Climate Change 2014 Synthesis Report. Intergovernmental Panel on Climate Change. Intergovernmental Panel on Climate Change

Johnson DDP, Jetz W, Macdonald DW (2002) Environmental correlates of badger social spacing across Europe. Journal of Biogeography 29(3):411-425

Kearney M, Shine R, Porter WP (2009) The potential for behavioral thermoregulation to buffer "cold-blooded" animals against climate warming. Proceedings of the National Academy of Sciences of the United States of America 106(10):38353840

Keith DA, Akçakaya HR, Thuiller W, Midgley GF, Pearson RG, Phillips SJ, Regan HM, Araújo MB, Rebelo TG (2008) Predicting extinction risks under climate change: coupling stochastic population models with dynamic bioclimatic habitat models. Biology letters 4(5):560-563

Kowalczyk R, Jedrzejewska B, Zalewski A (2003) Annual and circadian activity patterns of badgers (Meles meles) in Białowieża Primeval Forest (eastern Poland) compared with other Palaearctic populations. Journal of Biogeography 
$30(3): 463-472$

Macdonald DW, Newman C (2002) Population dynamics of badgers (Meles meles) in Oxfordshire, U.K.: numbers, density and cohort life histories, and a possible role of climate change in population growth. Journal of Zoology 256(01):121-138

Macdonald DW, Newman C, Buesching CD, Nouvellet P (2010) Are badgers 'Under The Weather'? Direct and indirect impacts of climate variation on European badger (Meles meles) population dynamics. Global change biology 16(11):29132922

Macdonald DW, Newman C, Buesching CD (2015) Badgers in the rural landscape - conservation paragon or farmland pariah? Lessons from the Wytham Badger Project. In: Farming and Wildlife. Conflict in the countryside, Oxford University Press, Oxford, pp 65-94

McClune DW, Marks NJ, Delahay RJ, Montgomery WI, Scantlebury DM (2015) Behaviour-time budget and functional habitat use of a free-ranging European badger(Meles meles). Animal Biotelemetry 3(1):193

Moss RH, Edmonds JA, Hibbard KA, Manning MR, Rose SK, van Vuuren DP, Carter TR, Emori S, Kainuma M, Kram T, Meehl GA, Mitchell JFB, Nakicenovic N, Riahi K, Smith SJ, Stouffer RJ, Thomson AM, Weyant JP, Wilbanks TJ (2010) The next generation of scenarios for climate change research and assessment. Nature 463(7282):747-756

Murphy JM, Sexton DHM, Jenkins GJ, et al (2009) UK Climate Projections Science Report: Climate Change Projections . UK Met Office

Nakicenovic N, Swart R (2000) Special Report on Emissions Scenarios: A Special Report to the IPCC. Cambridge Univ. Press, Cambridge

Newman C, Macdonald DW (2015) Biodiversity Climate change impacts report card Technical paper 2. The Implications of climate change for terrestrial UK Mammals. . UK Natural Environment Research Council

Newman C, Buesching CD, Macdonald DW (2017) Meline Mastery of Meteorological Mayhem: The effects of climate changeability on European badger population dynamics. In: Macdonald DW, Newman C, Harrington LA (eds) The Biology and Conservation of Wild Mustelids, Oxford University Press, Oxford, pp 420-433

Noonan MJ, Markham A, Newman C, Trigoni N, Buesching CD, Ellwood SA, Macdonald DW (2014) Climate and the individual: inter-annual variation in the autumnal activity of the European badger (Meles meles). PLoS ONE 9(1):e83156

Noonan MJ, Newman C, Trigoni N, Buesching CD (2015a) A new MagnetoInductive tracking technique to uncover subterranean activity: what do animals do underground? Methods in Ecology and Evolution 6(5):510-520

Noonan MJ, Rahman MA, Newman C, Buesching CD, Macdonald DW (2015b) Avoiding verisimilitude when modelling ecological responses to climate change: the influence of weather conditions on trapping efficiency in European badgers (Meles meles). Global change biology 21(10):3575-3585

Nouvellet P, Newman C, Buesching CD, Macdonald DW (2013) A Multi-Metric Approach to Investigate the Effects of Weather Conditions on the Demographic of a Terrestrial Mammal, the European Badger (Meles meles). PLoS ONE 8(7):e68116

Oliver TH, Morecroft MD (2014) Interactions between climate change and land use change on biodiversity: attribution problems, risks, and opportunities. Wiley Interdisciplinary Reviews: Climate Change 5(3):317-335 
Pinheiro J, Bates D, DebRoy S, Sarkar D, R Core Team (2013) Linear and Nonlinear Mixed Effects Models [R package nlme version 3.1-131]

Pretzlaff I, Dausmann KH (2012) Impact of Climatic Variation on the Hibernation Physiology of Muscardinus avellanarius. In: Living in a Seasonal World, Springer Berlin Heidelberg, Berlin, Heidelberg, pp 85-97

Quintero I, Wiens JJ (2013) Rates of projected climate change dramatically exceed past rates of climatic niche evolution among vertebrate species. Ecology letters 16(8):1095-1103

R Core Team (2016) R: A language and environment for statistical computing.

Rolandsen CM, Solberg EJ, Herfindal I, Van Moorter B, Sæther BE (2011) Largescale spatiotemporal variation in road mortality of moose: Is it all about population density? Ecosphere 2(10):1-12

Rosenheim JA, Tabashnik BE (1991) Influence of Generation Time on the Rate of Response to Selection. The American Naturalist 137(4):527-541

Scheffers BR, De Meester L, Bridge TCL, Hoffmann AA, Pandolfi JM, Corlett RT, Butchart SHM, Pearce-Kelly P, Kovacs KM, Dudgeon D, Pacifici M, Rondinini C, Foden WB, Martin TG, Mora C, Bickford D, Watson JEM (2016) The broad footprint of climate change from genes to biomes to people. Science 354(6313):aaf7671

Schloss CA, Nuñez TA, Lawler JJ (2012) Dispersal will limit ability of mammals to track climate change in the Western Hemisphere. Proceedings of the National Academy of Sciences of the United States of America 109(22):8606-8611

Settele J, Betts RA, Bunn S, Nepstad D, Overpeck JT, Taboada MA (2014) Terrestrial and Inland Water Systems. In: Dokken DJ, Bilir TE, Chatterjee KL, Ebi YO, Estrada RC, Genova BG, Kissel ES, Levy AN, MacCracken S, Mastrandrea PR, White LL (eds) Climate Change Impacts, Adaptation, and Vulnerability. Part A Global Sectoral ASpects. Contribution of Working Group II to the Fifth Assessment Report of the Intergovernmental Panel on Climate Change, http://www.cambridge.org/au/academic/, Cambridge, United Kingdom, pp 271-359

Sexton D, Richardson K, Harris G, Karmalkar A, Murphy J, Brown S, Tinker J (2016) Assessment of UKCP09, including comparison against IPCC CMIP5 multi-model simulations. Met Office Hadley Centre Technical Note no. 99

Sih A, Ferrari MCO, Harris DJ (2011) Evolution and behavioural responses to human-induced rapid environmental change. Evolutionary applications $4(2): 367-387$

Smit B, Burton I, Klein RJT, Wandel J (2000) An Anatomy of Adaptation to Climate Change and Variability. Climatic Change 45:223-251

Sommer R, Benecke N (2004) Late- and Post-Glacial history of the Mustelidae in Europe. Mammal Review 34(4):249-284

Tinnesand HV, Buesching CD, Noonan MJ, Newman C, Zedrosser A, Rosell F, Macdonald DW (2015) Will Trespassers Be Prosecuted or Assessed According to Their Merits? A Consilient Interpretation of Territoriality in a Group-Living Carnivore, the European Badger (Meles meles). PLoS ONE 10(7):e0132432

Tsunoda M, Newman C, Buesching CD, Macdonald DW, Kaneko Y (2018) Badger setts provide thermal refugia, buffering changeable surface weather conditions. Journal of Thermal Biology 74:226-233

Visser ME (2008) Keeping up with a warming world; assessing the rate of adaptation to climate change. Proceedings of the Royal Society B: Biological Sciences 
275(1635):649-659

Walther GR, Post E, Convey P, Menzel A, Parmesan C, Beebee TJC, Fromentin JM, Hoegh-Guldberg O, Bairlein F (2002) Ecological responses to recent climate change. Nature 416(6879):389-395

Wilson RP, White CR, Quintana F, Halsey LG, Liebsch N, Martin GR, Butler PJ (2006) Moving towards acceleration for estimates of activity-specific metabolic rate in free-living animals: the case of the cormorant. Journal of Animal Ecology 75(5):1081-1090

Woodroffe R, Macdonald DW (1995) Costs of breeding status in the European badger, Meles meles. Journal of Zoology 235(2):237-245 